\title{
Postoperative sudden sensorineural hearing loss after posterior lumbar decompression: a case report
} [Une perte auditive neurosensorielle soudaine suivant la décompression lombaire postérieure : une étude de cas]

Peter H.K. Mak FrCA, Paul S. Tumber FrCPC

Purpose: We report a case in which a patient sustained a dural tear during spinal surgery under general anesthesia complicated by a severe and persistent unilateral sensorineural hearing loss.

Clinical findings: A $5 \mathrm{I}$-yr-old man with no previous otological history underwent a posterior lumbar decompression surgery in the prone position under general anesthesia. A small dural tear was discovered intra-operatively and was repaired by sutures. Surgery lasted for eight hours with over $3 \mathrm{~L}$ of blood loss. Recovery from anesthesia was otherwise uneventful. A unilateral right-sided sensorineural hearing loss was discovered shortly after completion of surgery. This was associated with mild tinnitus but no vertigo. There was no aural fullness, pain, headache or postural element to his symptoms. Despite extensive investigations, treatment and followup by an otorhinolaryngologist, his symptoms failed to improve 18 months following surgery.

Discussion: The possible etiologies, preventive strategies, prognosis and management plan of this rare complication are discussed.

Objectif : Nous présentons le cas d'un patient qui a subi, sous anesthésie générale, une lacération durale pendant une opération à la colonne vertébrale qui s'est compliquée par l'apparition d'une perte auditive neurosensorielle unilatérale sévère et persistante.

Éléments cliniques : Un homme de 5 I ans, sans antécédent auditif, a subi une décompression lombaire postérieure en décubitus ventral sous anesthésie générale. Une petite lacération peropératoire de la dure-mère a été découverte et réparée par des sutures. L'opération a duré huit heures et a comporté une perte sanguine de plus de $3 \mathrm{~L}$. Par ailleurs, la récupération de l'anesthésie a été sans incident. Une perte auditive neurosensorielle unilatérale droite a été découverte peu après la fin de l'opération. Elle s'accompagnait d'acouphènes, non de vertige. Les symptômes ne comprenaient pas de sensation de plénitude auriculaire, de douleur, de céphalée ou d'élément postural. Malgré une investigation poussée, le traitement et le suivi par un oto-rhino-laryngologiste, les symptômes persistaient 18 mois après l'opération.

Discussion : Les causes possibles, les stratégies préventives, le pronostic et le plan thérapeutique de cette complication rare sont discutées.

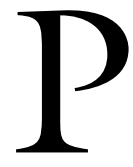

OSTOPERATIVE hearing loss following general anesthesia is rare (5-20:100,000) and has mostly been reported in patients following cardiopulmonary bypass (CPB). ${ }^{1}$ For patients undergoing subarachnoid anesthesia or intradural surgery, the loss of cerebral spinal fluid (CSF) and hence the drop in intracranial pressure (ICP) can result in hearing loss and cranial nerve palsy. ${ }^{2}$ We report a case in which a patient sustained a dural tear during spinal surgery under general anesthesia complicated by a severe and persistent unilateral sensorineural hearing loss.

\section{Clinical findings}

A 51-yr-old man with a history of spondylolisthesis underwent a L3 to S1 posterior decompression and fusion. His past medical history was significant for mild asthma, urolithiasis and acute rheumatic fever as a child. He had no history of preoperative otologic disease or symptoms of auditory dysfunction. There was no history of medications that are susceptible to hearing impairment such as aminoglycosides or diuretics.

General anesthesia was induced by fentanyl $250 \mu \mathrm{g}$, propofol $200 \mathrm{mg}$ and muscle relaxation by rocuronium $50 \mathrm{mg}$. A $20-\mathrm{G}$ arterial catheter was inserted into

From the Department of Anesthesia, Toronto Western Hospital, University of Toronto, Toronto, Ontario, Canada.

Address correspondence to: Dr. Peter H.K. Mak, Department of Anesthesia, Toronto Western Hospital, 399 Bathurst Street, University

Health Network, University of Toronto, Toronto, Ontario M5T 2S8, Canada. Phone: 416-603-5118; Fax: 416-603-6494;

E-mail: peter.mak@uhn.on.ca

Accepted for publication November 21, 2002.

Revision accepted February 12, 2003. 
his right radial artery and a central venous catheter into the right internal jugular vein. He was placed in the prone position on the Jackson operating table (Orthopedic Systems Inc, CA, USA) for surgery. Anesthesia was maintained with nitrous oxide and desflurane in oxygen with intermittent doses of fentanyl. Somato-sensory evoked potential (SSEP) and electromyelography (EMG) were applied. Shortly after spinal decompression, a small central dural tear at the mid-sacral level was noticed. It was immediately repaired by 4-0 nylon (Polyamid) sutures. A brief Valsalva maneuver to $30 \mathrm{~cm} \mathrm{H}_{2} \mathrm{O}$ was performed to confirm the integrity of the repair. The total surgical time was eight hours with no significant SSEP or EMG changes. The estimated blood loss was 3250 $\mathrm{mL}$ and $6000 \mathrm{~mL}$ crystalloid, $1000 \mathrm{~mL}$ colloid, $3 \mathrm{U}$ of packed red blood cells and $1570 \mathrm{~mL}$ cell-saver blood were administered. No intentional controlled hypotension was required.

The patient developed a severe right-sided hearing deficit shortly after surgery. This was associated with some tinnitus but no vertigo, sensation of aural fullness or pain. Saline syringing to the external auditory canals was performed with no improvement. Weber and Rinnie tests confirmed sensorineural hearing loss. An otorhinolaryngology consultation confirmed an otherwise normal physical and neurological examination. There was no postdural puncture headache or any postural symptom. A subsequent audiogram showed a profound right-sided sensorineural hearing loss (Figure). This impairment spanned over the entire frequency range examined. The tinnitus resolved over the next two days. Six months after surgery, a magnetic resonance imaging (MRI) scan failed to show an identifiable mass lesion. Over the next 18 months, his hearing loss persisted with no significant improvement.

\section{Discussion}

Sudden sensorineural hearing loss (SSNHL) following $\mathrm{CPB}$ was thought to be the result of micro-emboli, calcium, fat and particulate matter deposition. ${ }^{3}$ Hypoperfusion causing infarction to the basilar circulation during the time of extracorporeal circulation is also possible. Cranial nerve palsy and SSNHL after subarachnoid anesthesia is thought to be the result of CSF loss and hence an ICP drop creating a pressure imbalance. $^{2}$ The abducens (CNVI), facial (CNVII) and the vestibulocochlear (CNVIII) nerves are predominantly affected. As the eighth nerve enters the tight internal acoustic meatus after crossing the posterior cranial fossa, it can be predisposed to compression injury as the brain sags after pressure changes while in the prone position. Larger size needles with sharp

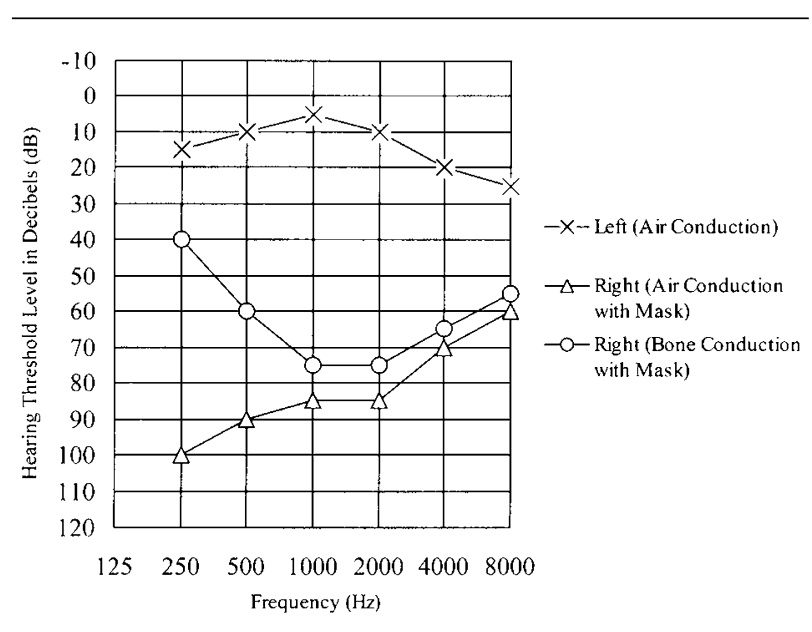

FIGURE Audiogram of the patient one month after surgery.

puncture points are also thought to be risk factors. ${ }^{4}$ Early detection and correction of pressure changes have been suggested but in this case, despite a prompt repair of the dural tear, we still failed to prevent the development of SSNHL.

The Valsalva maneuver may sustain an intrathoracic pressure of up to $35 \mathrm{~cm}$ of water. During nitrous oxide administration, middle ear pressure can even reach 45 $\mathrm{cm}$ of water. ${ }^{5}$ The force that applies to the middle ear can disrupt the cochlear membrane to form a perilymph fistula. This fistula allows fluid to drain between the inner and the middle ear. Surgery is required to patch the oval and the round windows.

Persistent CSF leak is also a possibility in this patient. However, frequent physical examination and a subsequent MRI scan failed to confirm this.

Younger patients are also more prone to SSNHL following subarachnoid anesthesia. Patients that are younger have a higher incidence than the elderly probably related to their difference in CSF leakage. ${ }^{6}$ The amount of blood loss and hence fluid replacement is also correlated to low frequency hearing loss. Acute changes in blood volume, ICP and osmolarity are thought to be triggering factors. ${ }^{7}$

Preventive approaches may include the avoidance of nitrous oxide and the Valsalva maneuver in patients with a history of auditory dysfunction, dysequilibrium or vertigo. However, to date, there is still no definitive evidence to support this and no precise recommendation regarding maximum pressures acceptable to these patients.

The management of SSNHL following surgery is inconclusive. Results of the use of steroids, anti-viral agents, iv fluids, vasodilators and antidiuretics have 
been variable. ${ }^{8} \mathrm{~A}$ recent study reported a higher incidence of success in using cervico-thoracic epidural compared to stellate ganglion block. A higher blood flow to the cochlear region may be the main mechanism. ${ }^{9}$ Although the incidence of acoustic neuroma in the cochlear and the cerebello-pontine region is small, a MRI scan is still recommended as surgery may become necessary. Some even recommend auditory brainstem response for retrocochlear lesions. The necessity of surgical intervention is unresolved. Most otologists prefer not to operate if the hearing loss has stabilized. The extent of recovery is also uncertain. The risk factors leading to poor prognosis include initial severity, timing of intervention and treatment, vestibular symptoms and the affected range of audiographic frequencies. ${ }^{10}$

In conclusion, we report a case of persistent SSNHL in a patient following spinal surgery. This report serves to remind clinicians that SSNHL is a poorly understood postoperative complication. Preventive strategies are limited and a better understanding of this devastating condition is crucial to improve our safety profile.

\section{References}

1 Evan KE, Tavill MA, Goldberg AN, Silverstein $H$. Sudden sensorineural hearing loss after general anesthesia for nonotologic surgery. Laryngoscope 1997; 107: 747-52.

2 Wang LP. Sudden bilateral hearing loss after spinal anaesthesia. A case report. Acta Anaesthesiol Scand 1986; 30: 412-3.

3 Walsted A, Andreassen UK, Berthelsen PG, Olesen A. Hearing loss after cardiopulmonary bypass surgery. Eur Arch Otorhinolaryngol 2000; 257: 124-7.

4 Malhotra SK, Joshi M, Grover S, Sharma SC, Dutta A. Auditory function following spinal analgesia. Comparison of two spinal needles. Eur J Anaesthesiol 2002; 19: 69-72.

5 Girardi FP, Cammisa FP Jr, Sangani PK, et al. Sudden sensorineural hearing loss after spinal surgery under general anesthesia. J Spinal Disord 2001; 14: 180-3.

6 Gultekin S, Ozcan S. Does hearing loss after spinal anesthesia differ between young and elderly patients? Anesth Analg 2002; 94: 1318-20.

7 Schaffartzik W, Hirsch J, Frickmann F, Kubly P, Ernst $A$. Hearing loss after spinal and general anesthesia: a comparative study. Anesth Analg 2000; 91: 1466-72.

8 Eisenman DJ, Arts $H A$. Effectiveness of treatment for sudden sensorineural hearing loss. Arch Otolaryngol Head Neck Surg 2000; 126: 1161-4.

9 Fujino M, Hisashi K, Yashima N, et al. Treatment of sudden sensorineural hearing loss with a continuous epidural block. Eur Arch Otorhinolaryngol 1999; 256(Suppl): S18-21.

10 Ito $S$, Fuse T, Yokota M, et al. Prognosis is predicted by early hearing improvement in patients with idiopathic sudden sensorineural hearing loss. Clin Otolaryngol 2002; 27: 501-4. 